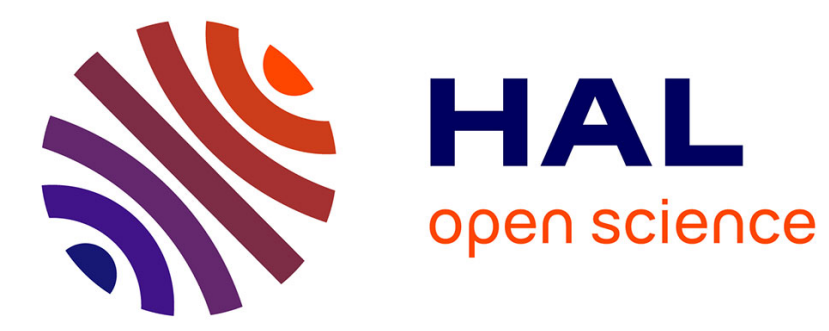

\title{
DIFFUSION BARRIER LAYERS FOR OHMIC CONTACTS TO GaAs
}

\author{
D. Allan, J. Herniman, M. Gilbert, P. O'Sullivan, M. Grimshaw, A. \\ Station-Bevan
}

\section{- To cite this version:}

D. Allan, J. Herniman, M. Gilbert, P. O'Sullivan, M. Grimshaw, et al.. DIFFUSION BARRIER LAYERS FOR OHMIC CONTACTS TO GaAs. Journal de Physique Colloques, 1988, 49 (C4), pp.C4-427-C4-430. 10.1051/jphyscol:1988490 . jpa-00227988

\section{HAL Id: jpa-00227988 https://hal.science/jpa-00227988}

Submitted on 1 Jan 1988

HAL is a multi-disciplinary open access archive for the deposit and dissemination of scientific research documents, whether they are published or not. The documents may come from teaching and research institutions in France or abroad, or from public or private research centers.
L'archive ouverte pluridisciplinaire HAL, est destinée au dépôt et à la diffusion de documents scientifiques de niveau recherche, publiés ou non, émanant des établissements d'enseignement et de recherche français ou étrangers, des laboratoires publics ou privés. 
DIFFUSION BARRIER LAYERS FOR OHMIC CONTACTS TO GAAS

D.A. ALLAN, J. HERNIMAN, M.J. GILBERT, P.J. O'SULLIVAN, M.P. GRIMSHAW* and A.E. STATON-BEVAN*

British Telecom Research Laboratories, Martlesham Heath, Ipswich, Great-Britain

"Dept. of Materials, Imperial College, GB-London SW7 $2 \mathrm{AZ}$, Great-Britain

\begin{abstract}
Résumé
Dans les circuits intégrés a transistors métal-semiconducteurs de AsGa, on s'est servi de barrières de diffusion par-dessus les contacts ohmiques alliés Ni-Au-Ge et "non alliés" Pd-Ge. Ceci empêche la diffusion des couches d'interconnexion suivantes et assure la stabilité et la basse resistance $(0.05 \mathrm{ohm} . \mathrm{mm})$ des contacts. L'évaluation de ces structures de contact du point de vue électrique ainsi que par AES et par TEM est présentée ici. Les résultats montrent que l'effet de barrière produit des contacts uniformes et faibles et un bon rendement de circuits numériques rapides à intégration à echelle moyenne. (MSI).
\end{abstract}

\begin{abstract}
Barrier layers have been used on top of $\mathrm{Ni}-\mathrm{Au}-\mathrm{Ge}$ alloyed and Pd-Ge "nonalloyed" ohmic contacts for GaAs MESFET integrated circuits. They prevent diffusion of subsequent interconnection layers and so maintain stable low resistance $(0.05 \mathrm{ohm} . \mathrm{mm})$ contacts. The assessment of these contact structures, both electrically and using AES and TEM, is presented. The results show that the barrier action is effective in producing uniform and reliable contacts and good yields of MSI high speed digital circuits.
\end{abstract}

\title{
1 - INTRODUCTION
}

Ohmic contacts to GaAs using the $\mathrm{Ni}-\mathrm{Au}-\mathrm{Ge}$ alloyed system have been popular for many years and have been successfully used in MESFET integrated circuits for low resistance source and drain contacts. The contact morphology and reproducibility of these contacts can be rather variable and to improve these aspects we previously used an evaporated silicon dioxide dielectric encapsulating layer during the alloying process / $/$. This prevented surface tension effects degrading the contact edge definition and also encouraged more even alloying of the contact. This approach had the disadvantage that the $\mathrm{sio}_{2}$ had to be removed after alloying, leaving the contact open to subsequent degradation during processing.

A more attractive option is to use a conductive barrier layer which can be left in place and, on top of which, an interconnect layer can be deposited in the same deposition cycle as the ohmic contact layers. The barrier has to be capable of remaining intact during ohmic contact formation, not allowing interdiffusion of the top interconnect metal. This maintains the stoichiometry of the underlying layers to preserve the integrity of the ohmic contact. The barrier layer also has to have good adhesion properties and must be stable during subsequent device processing. A further important requirement of the contact is good surface and edge morphology for subsequent photolithographic alignment of sub-micron features. We have investigated a large number of possible barrier materials but only three, zirconium diboride ( $\mathrm{zr}_{2}$ ), tungsten silicide $\left(W_{5} \mathrm{Si}_{3}\right)$ and tungsten nitride (WN) fulfilled these conditions.

The fabrication of $\mathrm{Ni-Au-Ge}$ alloyed and also Pd-Ge non-alloyed ohmic contacts is described in the following section. Pd-Ge contacts have the advantage that they are formed by solid phase epitaxy to give smoother interfaces and do not contain $A u$, a potential reliability hazard. The electrical characteristics of the contacts, their uniformity and stability and the resulting MESFET device

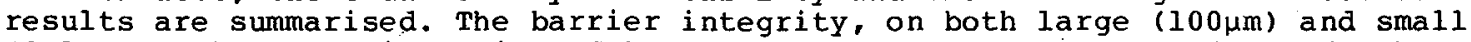
$(0.1 \mu \mathrm{m})$ scales, was investigated by Auger Electron Spectroscopy (AES) depth profiling and Transmission Electron Microscopy (TEM) cross-sectional analyses resnectivelv. 


\section{2 - EXPERIMENTAL}

Semi-insulating GaAs substrates, ion-implanted with si to give a peak doping level of $1 * 10^{18} \mathrm{~cm}^{-3}$, were used to give comparable conditions to the FET source and drain regions. The alloyed ohmic contact layers of $\mathrm{Ni}(5 \mathrm{~nm}), \mathrm{Au}(45 \mathrm{~nm}), \mathrm{Ge}$ $(20 \mathrm{~nm})$ or the non-alloyed $\mathrm{Pd}(50 \mathrm{~nm})$ and $\mathrm{Ge}(100 \mathrm{~nm})$ layers were deposited by electron beam evaporation at a pressure < $1 * 10^{-6}$ mbar. $\mathrm{zrB}$, was also evaporated, rather than sputtered as in initial reports for silicon technology $/ 2 /$, so that it could be incorporated in the same deposition sequence. A thin Au layer was also deposited on top of the barrier layer to give a low resistivity surface for ease of measurements and subsequent layer contacting. Thus the total ohmic contact structure can be deposited in a single evaporation sequence and defined by conventional photolithographic lift-off techniques. The $\mathrm{W}_{5} \mathrm{Si}_{3}$ and $\mathrm{WN}$ were sputtered in order to retain a constant stoichiometry. Lift- $\mathrm{ff}^{3}$ of these materials was still possible using a specially developed two level resist technology.

Heat treatment of the ohmic contacts was carried out on a carbon strip heater in flowing forming gas or in an optical annealing system in flowing argon /3/. The contact resistance was measured using the transmission line model (TLM) /4/ by extrapolation of resistance for zero contact pad separation and normalised to a lmm wide contact and thus expressed in ohm.mm. Low contact resistivities (ohm. $\mathrm{cm}^{2}$ ) are difficult to calculate accurately since the models assume specific current paths and doping values. The contact resistance is also more useful and easily applied to the parastic resistance of a MESFET.

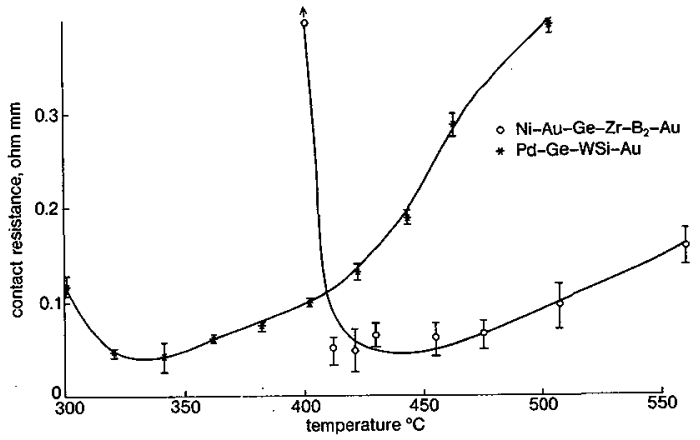

Fig 1 Contact resistance vs temperature of heat treatment for ohmic contact systems.

Figure 1 shows the contact resistance obtained as a function of heat treatment for both Ni-Au-Ge and Pd-Ge contacts with different diffusion barrier layers. The minima in contact resistance are in the same temperature range as Au-Ge$\mathrm{Ni} / 1 /$ and $\mathrm{Pd}-\mathrm{Ge} / 5,6 /$ without barrier layers, indicating that the barrier layers are effective and play only a secondary role in the contact formation. The minimum values of $0.06 \mathrm{ohm} . \mathrm{mm}$ at $440^{\circ} \mathrm{C}$ for $\mathrm{Ni}-\mathrm{Au}-\mathrm{Ge}$ and $0.04 \mathrm{ohm} . \mathrm{mm} \mathrm{at}$ $330^{\circ} \mathrm{C}$ for Pd-Ge are amongst the lowest values ever reported. Particular care was taken to ensure that lithographic dimensional errors were accounted for since a difference of $0.4 \mu \mathrm{m}$ in pad separation is equivalent to $0.03 \mathrm{ohm} . \mathrm{mm}$ which is significant. Each point represents the mean of 16 devices in the case of $\mathrm{Ni}-\mathrm{Au}-\mathrm{Ge}$ and 6 in the case of Pd-Ge and the error bars indicate the total spread in measurements. A similar uniformity is exhibited over a whole 50mm diameter wafer with the contact structure Ni-Au-Ge-ZrB ${ }_{2}^{-A u}$ which has a mean of $0.07 \mathrm{ohm}$.mm and a standard deviation of $0.02 \mathrm{ohm} . \mathrm{mm}$. A histogram showing similar results with a WN barrier layer is illustrated in figure 2 .

AES sputter etch profiling was used to check the integrity of the barrier and in all cases abrupt interfaces between the layers were observed after ohmic contact formation. A typical depth profile for a Pd-Ge-WSi-Au stucture is shown in figure 3. The AES technique uses an analysis area up to $100 \mu \mathrm{m}$ in diameter, much greater than the average device area, and so only the average structure is revealed. In order to ensure that the barrier was effective and did not show small areas of breakdown which would be significant on a device $(0.1 \mu \mathrm{m})$ scale, cross-sectional TEM (XTEM) samples were prepared using Ar lon beam thinning and examined in a Jeol JEM $2000 \mathrm{FX}$ microscope with EDX analysis. 


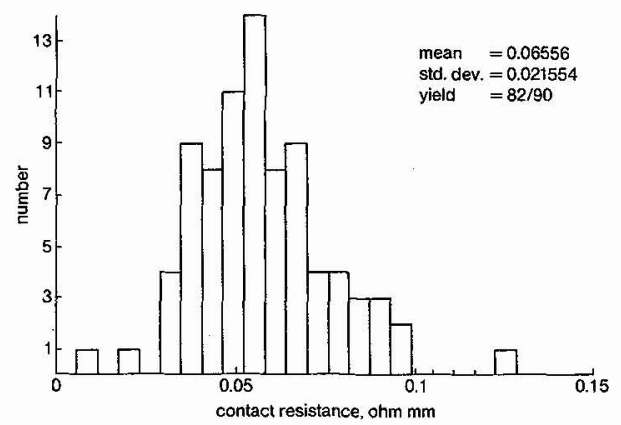

Fig 2 Histogram of contact resistance measurements across a wafer for the $\mathrm{Ni-Au-Ge-WN-Au} \mathrm{system.}$

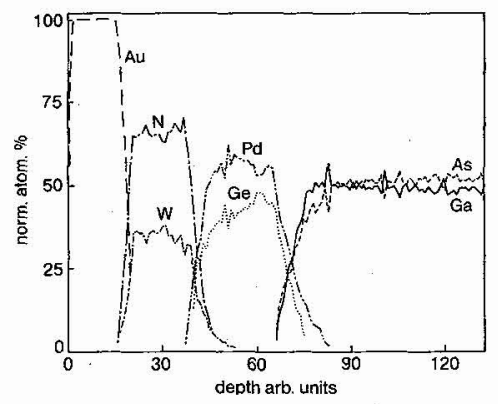

Fig 3 AES depth profile for the Pd-Ge-WSi-Au showing the separation of the PdGe from the Au by the barrier layer.

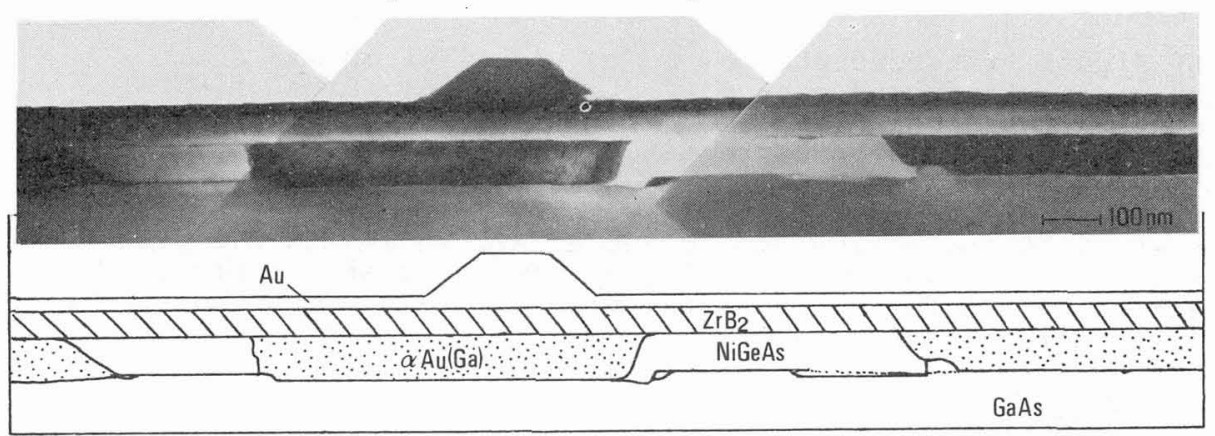

Fig 4 TEM cross-section of an optically annealed Ni-Au-Ge-ZrB ${ }_{2}-\mathrm{Au}$ contact. The schematic diagram shows the phases present.
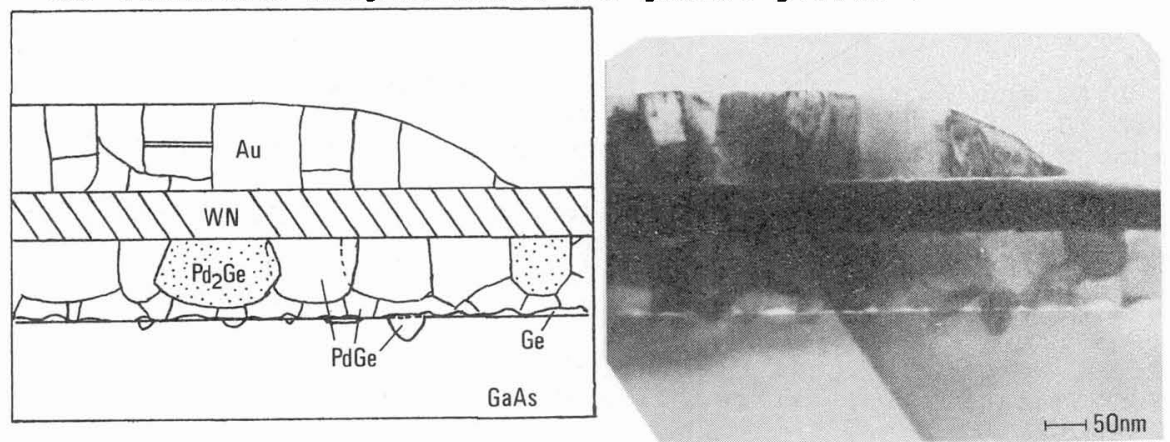

Fig 5 - TEM cross-section of an optically annealed Ge-Pd-WN-Au contact. The schematic diagram shows the phases present. 
The XTEM study of the Ni-Au-Ge-ZrB,-Au system, fig 4, showed the amorphous $\mathrm{ZrB}$ layer to be an effective barrler. Occasionaliy, however, $\mathrm{zr}$ from the bartier was observed to have undergone a limited planar reaction with adjacent $\mathrm{Au}$ rich phases forming $\mathrm{Au} \mathrm{Zr}$. The phases which were present in both the optically annealed and carbon strip annealed contacts included; orthorhombic $\mathrm{NiGe,} \mathrm{hexagonal} \mathrm{NiGeAs,} \mathrm{cubic} \mathrm{epitaxial} \mathrm{Ge,} \mathrm{cubic} \alpha$ Au-Ga and hexagonal $\alpha$ ' $\mathrm{Au}-\mathrm{Ga}$. The carbon strip heated samples contained additional, Ga-rich Au-Ga phases, hexagonal $B+B, A u-G a$ and orthorhombic $A u_{2} G a$. These phases probably resulted from the longer anneal time of $60 \mathrm{~s}$ (cf. 5 s for optical annealing). The diffusion depth of the metallisation into the GaAs was 0-15 $\mathrm{nm}$ and $45 \mathrm{~nm}$ for the optically and carbon strip annealed samples respectively. These values compare favourably with the 70-110 nm values quoted for Ni-Au-Ge contacts without diffusion barriers $/ 8 /$.

Fig 5 shows a typical XTEM of the Ge-Pd-WN-Au system. The fine polycrystalline WN barrier layer was found to be intact and unreacted. The top Au layer (f.c.c.) contained horizontal twin boundaries. The lower contact structure consisted of an upper layer of large PdGe and Pd Ge grains and a lower layer of smaller PdGe grains. A thin (<10nm) layer of epitaxial Ge exists at the GaAs interface through which some of the PdGe grains protruded up to $30 \mathrm{~nm}$ into the GaAs. It is thought that the rough two-layer morphology is a product of the short annealing time and not an effect due to the barrier.

The barriers have also proved to be effective during subsequent device fabrication which involves further high temperature processes and also during deliberate temperature stressing at $300^{\circ} \mathrm{C}$ for periods up to $100 \mathrm{~h}$. No changes in contact resistance were observed within the measurement accuracy for the $\mathrm{Ni}-\mathrm{Au}-\mathrm{Ge}$ system but the $\mathrm{Pd}-\mathrm{Ge}$ resistance increased to $0.23 \mathrm{ohm} . \mathrm{mm}$. This is not surprising considering the sintering temperature was only $330^{\circ} \mathrm{C}$. The incorporation of $\mathrm{ZrB}_{2}$ barrier layer ohmic contacts in MSI scale circuits has proved satisfactory $Z_{n}$ over 100 wafers. These had additional Ti-Pt-Au layers on top of the ohmic contact for interconnection between devices. There is no evidence of interdiffusion of these different layers in contrast to the report of interdiffusion when no barrier layer was included $/ 7 /$.

MESFETs with the following parameters were regularly achieved;-

Small signal transconductance
Large signal transconductance
Saturation threshold voltage
Source-drain saturation current

$$
\begin{aligned}
\left(g_{\mathrm{m}}\right) & =151 \mathrm{~ms} / \mathrm{mm} \\
\left(G_{\mathrm{m}}\right) & =104 \mathrm{~ms} / \mathrm{mm} \\
\left(\mathrm{V}_{\mathrm{T}}\right) & =-2.05 \mathrm{~V} \\
\left(\mathrm{I}_{\mathrm{dss}}\right) & =213 \mathrm{~mA} / \mathrm{mm}
\end{aligned}
$$

The drift in the above parameters was within $+/-28$ after temperature stressing at $300^{\circ} \mathrm{C}$ for periods up to $100 \mathrm{~h} / 3 /$. These MESFETs were used in $8: 1$ multiplexer and demultiplexer circuits operating at speeds of $1.8 \mathrm{Gbit} / \mathrm{s}$ or greater and which had fully functional yields of $32 \%$ - the failures being due mainly to lithographic defects.

\section{3 - ACKNOWLEDGEMENTS}

The authors wish to thank Dr M Hill of BTRL for the AES analysis and the Director of Research at BTRL for permission to publish this work.

\section{REFERENCES}

/1/ Allan, D.A. and Thorp, S.C., Physica 129B (1985) 445 .

/2/ Shappiro, J., Sol. State Technology october (1985) 161.

/3/ Herniman, J., Allan, D.A. and O'sullivan, P.J., IEE Proc Part I Sol. State and Electron Devices 135 (1988) 67 .

/4/ Harrison, H. and Reeves, G., IEEE Elec. Dev. Letts. EDL-3 (1982) 111.

/5/ Marshall, E.D, Chen,W.X., Wu, C.S. and Lau, S.S., Appl. Phys. Lett. 47 (1985) 298 .

/6/ Kaminska, E., Piotrowska, A, Barcz, A., Turos, A. and Pietrak, R., Crys. Prop. and Prep. 12 (1987) 277.

/7/ Lee, C.P., Welch, B.M. and Fleming, W.P., Electron. Lett. 17 (1981) 407.

/8/ Shih,Y.C, Murakami,M., Wilkie, E.L. and Callegari,A.C., J. Appl. Phys. 62 (1987) 582 . 